Estudios Románicos, Volumen 28, 2019, pp. 259-268

ISSN: 0210-491

eISSN: 1989-614X

DOI: https://doi.org/10.6018/ER/3777071

\title{
EL USO DE LA ERUDICIÓN EN LAS CONTINUACIONES ARGUMENTALES DE LA CELESTINA
}

(The use of erudition in the plot progression of La Celestina)

\author{
Luis García Valiente* \\ (IES Bonifacio Sotos de Casas Ibáñez) \\ Antonia Martínez Pérez ${ }^{* *}$ \\ (Universidad de Murcia)
}

\begin{abstract}
The present article analyses the use of rhetoric (especially of erudite figures) in the sequels to La Celestina: La Segunda Comedia de Celestina (Feliciano de Silva, 1534), La Tercera Parte de la Tragicomedia de Celestina (Gaspar Gómez de Toledo, 1536) and La Tragicomedia de Lisandro y Roselía (Sancho de Muñón, 1542), in order to establish a comparison with each other as well as with the primal work. To do it, this analysis focuses on aspects such as the number and kind of erudite figures, their accumulation and positioning, the characters who use them or the goals they aim at. Moreover, a few synoptic charts have been added to classify the named figures in each one of the sequels for a better understanding of their scope and significance.
\end{abstract}

Keywords: Erudition; Plot Progression; La Celestina; Feliciano de Silva; Gaspar Gómez de Toledo; Sancho de Muñón.

Resumen: El presente artículo analiza el uso del retoricismo (especialmente de las citas eruditas) en las continuaciones argumentales de La Celestina: La Segunda Comedia de Celestina (Feliciano de Silva, 1534), La Tercera Parte de la Tragicomedia de Celestina (Gaspar Gómez de Toledo, 1536) y La Tragicomedia de Lisandro y Roselia (Sancho de Muñón, 1542) con el fin de establecer comparaciones entre sí y respecto a la obra modelo. Para ello, este estudio se centra en aspectos como el número y tipo de citas eruditas, su acumulación y colocación, los personajes que las utilizan o la finalidad que preten-

\footnotetext{
* Dirección para correspondencia: Luis García Valiente. Departamento de Lengua Castellana y Literatura. IES Bonifacio Sotos. C/Las Monjas, 39. 02200 Casas Ibáñez, Albacete (1.garciavaliente@um.es).

** Antonia Martínez Pérez. Departamento de Filología Francesa, Románica, Italiana y Árabe. Facultad de Letras. Universidad de Murcia. Campus La Merced. 30071 Murcia (antonmar@um.es).
} 


\section{Luis García Valiente / IES Bonifacio Sotos de Casas Ibáñez Antonia Martínez Pérez / Universidad de Murcia}

den. Asimismo, se incorporan cuadros sinópticos que clasifican dichas citas en cada una de las continuaciones, para una mejor comprensión de su alcance y significado.

Palabras clave: Erudición; Continuaciones argumentales; La Celestina; Feliciano de Silva; Gaspar Gómez de Toledo; Sancho de Muñón.

Me estuviera boquiabierta oyéndote, madre, de aquí a mañana ${ }^{1}$. (Feliciano de Silva, La Segunda Celestina)

Estas palabras que Paltrana dirige a Celestina reflejan claramente el sentir de miles de lectores, quienes, hechizados por la obra de Rojas y de su inmortal personaje, los encumbraron hasta un triunfo sin precedentes; sin embargo, ese enorme éxito también convirtió muy pronto a esta composición en un modelo digno de ser imitado. Surgen así (y hasta bien entrado el siglo XVII) abundantes versiones e imitaciones en las que queda patente la profunda huella del modelo seguido, pues muchos autores se fundamentan directamente tanto en los personajes de Fernando de Rojas como en la temática en la que se ven inmersos ${ }^{2}$.

Le debemos a Menéndez Pelayo (1943) ser el primero en agrupar esta variedad de composiciones bajo el nombre de "género celestinesco", e incluso, en calificar de ciclo el conjunto formado por la obra de Fernando de Rojas y por sus sucesivas continuaciones argumentales: La Segunda Comedia de Celestina, de Feliciano de Silva (Medina del Campo, 1534); la Tercera Parte de la Tragicomedia de Celestina, de Gaspar Gómez de Toledo (Medina del Campo, 1536); y la Tragicomedia de Lisandro y Roselia, llamada Elicia y por otro nombre quarta obra y tercera Celestina, de Sancho de Muñón (Salamanca, 1542)4.

Estas tres obras no se limitan únicamente a apropiarse de ciertos personajes y a continuar una historia ya conocida por el público, sino que también imitan muchos de sus rasgos formales y temáticos, pues no cabe duda de que un lector familiarizado con este género posee un "horizonte de expectativas" sobre lo que espera encontrarse. Uno de estos rasgos (aunque quizá sea de los más desapercibidos por tratarse de algo inmanente a la cultura renacentista) es el uso abusivo del retoricismo, especialmente de

1 (Silva 1988: 317).

2 Sobre la proliferación de este tipo de obras resultan muy clarificadoras las declaraciones del bachiller Alonso Martínez, quien en 1555 afirmaba que "no se tiene por contento el que no tiene en su casa cuatro o cinco Celestinas" (Gallardo 1863-89: 641).

3 A este respecto también resulta muy revelador el trabajo de Consolación Baranda y Vian Herrero (2007: 407-482).

4 Pierre Heugas amplió el número de obras que forman el ciclo (lo denomina su descendencia directa) incluyendo también La Tragedia Policiana (Sebastián Fernández, 1547), La Comedia Florinea (Juan Rodríguez Florián, 1554) y La Comedia Selvagia (Alonso de Villegas, 1554), defendiendo que algunos personajes están emparentados o relacionados con los de Rojas, tal y como ocurre con los personajes de los ciclos de las novelas de caballerías (Heugas 1973: 52).

5 Este concepto fue acuñado por Hans-Robert Jauss, y hace referencia a las expectativas que crea el lector ante una nueva obra por el establecimiento de equivalencias con otras obras similares. Jauss es el máximo exponente de la escuela alemana de la Estética de la Recepción (Universidad de Constanza), cuyo objetivo principal es partir del lector-receptor como elemento clave de la comprensión y explicación del fenómeno literario (Jauss 1987: 59-85). 
las citas eruditas. Por ello, en este estudio se analizará la utilización de dicho recurso en cada una de las tres continuaciones y se comparará con su uso en la obra modelo.

En La Celestina, Sempronio criticaba las alusiones mitológicas de Calisto ("Dexa, señor, esos rodeos, dexa essas poesías, que no es habla conveniente la que a todos no es común, la que todos no participan, la que pocos entienden" (Rojas 1994: 221)); y en $L a$ Segunda Celestina se multiplican las reconversiones de este tipo (sobre todo cuando los sirvientes escuchan los poemas o las lecturas de las cartas), mientras que estas críticas de los criados tienen su contrapartida en la conciencia de superioridad de sus señores (apreciable especialmente entre Felides-Pandulfo por un lado, y Polandria-Quincia por el otro). Pandulfo llega a exclamar: "pienso que estas locas y estos cavallerotes tienen otra lengua sobre sí, que no deven entender la nuestra pues que mofan della" (Silva 1988: 406). Sin embargo, debemos tener en cuenta que la complejidad de esos parlamentos no radica tanto en la continua demostración de conocimientos, sino en el uso de unos procedimientos lingüísticos propios de las clases elevadas que, como indica Consolación Baranda:

Se transponen a interlocutores no apropiados. [...] Este es el procedimiento tradicional de deformación paródica: aplicar un tema serio a personajes inadecuados, produciendo un efecto humorístico. De esta forma, Silva denuncia, por la vía del humor, la trivialización de la convención cancioneril y su forma de concebir las relaciones amorosas (Silva 1988: 70).

No obstante, resulta muy paradójico que estas reconversiones por parte de los criados se alternen con otro rasgo muy característico de este género: la existencia de frecuentes intervenciones donde personajes de bajo nivel social demuestran un exceso de erudición. Incluso se puede llegar a la incongruencia de que ambas tendencias convivan en un mismo personaje, y como ejemplo de ello contamos con el rufián Brumandilón, quien (al contrario de lo que nos haría suponer su burda formación, pero en consonancia con el resto de los personajes de La Tragicomedia de Lisandro y Roselia) cita en numerosas ocasiones a autores y mitos clásicos -algunos muy precisos-, pero acto seguido puede cometer errores increíbles, como cuando confunde a Homero con un hombre de armas (Muñón 2009: 290); o afirma no saber quién es Cupido (pese a que dos intervenciones más atrás era capaz de hablar de Dédalo, Ícaro o Vulcano).

En la obra modelo destaca Sempronio -aunque Lida de Malkiel lo disculpa por asumir el papel de ayo (1962: 332)-, pero menos justificables son ciertos comentarios de Pármeno, Celestina o el joven Tristán, lo que ha dado lugar a que gran parte de la crítica considere que con ello se rompe el realismo verosímil que preside la obra. Es de sobra conocido el gran trabajo en el que Lida de Malkiel lo explica afirmando que el lector moderno lo valora desde una visión anacrónica y que realmente se trataba de una convención natural en la época ${ }^{6}$.

Sin embargo, también es importante tener en cuenta otro rasgo a la hora de estudiar el retoricismo de estas obras: la densidad de citas eruditas. Esto se debe a que, en

$6 \quad$ Para este tema resulta muy interesante la lectura de López Izquierdo (2008: 165-189). 
ocasiones, el uso abusivo de la amplificatio en el tratamiento de ciertos temas puede provocar una sensación de hartazgo en el receptor ${ }^{7}$.

Por un lado, en La Segunda Celestina no encontramos una pesada erudición que trabe la agilidad de la trama con continuas pausas, sino que las citas se reparten a lo largo de la obra de forma totalmente homogénea. Así lo declara también Consolación Baranda: "es menor la frecuencia de los diálogos de tipo oratorio, lo que está en relación con la escasa presencia y relevancia de las citas eruditas; en este aspecto Silva se aleja de La Celestina y de otras imitaciones anteriores, como la Comedia Thebaida y la Penitencia de amor" (1988: 58).

El extremo contrario está representado por La Tragicomedia de Lisandro y Roselia, cuya consideración general siempre ha estado lastrada por las críticas a su pesada erudición. Así lo han declarado expertos como Menéndez Pelayo: "el gusto que domina en la obra es el de las antiguas comedias humanísticas, y de él proceden sus principales defectos, que se reducen a uno solo, el alarde de erudición fácil y extemporáneo. No necesitaba alegar a cada momento aforismos y centones de poetas y filósofos antiguos" (1943: 99); o Rosa Navarro Durán, quien afirma que "esa afición a las enumeraciones de ejemplos de la Antigüedad impide que la obra pueda mostrar toda la intensidad que lleva dentro" (Muñón 2009: 65). Pero, ¿realmente son tan abundantes esas citas eruditas? Para ilustrarlo, hemos partido de una lectura atenta de las distintas composiciones y hemos realizado estas tres tablas en las que se comparan el número de citas eruditas en las tres obras objeto de estudio y en cada uno de sus personajes:

Tabla sobre las citas eruditas de La Segunda Celestina

\begin{tabular}{|c|c|c|c|c|}
\hline Personaje / Apartado & Antigüedad Clásica & Tradición Cristiana & $\begin{array}{c}\text { Edad Media y } \\
\text { Época Coetánea }\end{array}$ & TOTAL \\
\hline Celestina & 30 & 23 & 2 & $\mathbf{5 5}$ \\
\hline Pandulfo & 7 & 10 & - & $\mathbf{1 7}$ \\
\hline Felides & 15 & 1 & - & $\mathbf{1 6}$ \\
\hline Sigeril & 11 & 3 & - & $\mathbf{1 4}$ \\
\hline Poncia & 5 & 4 & - & $\mathbf{9}$ \\
\hline Polandria & 6 & - & - & $\mathbf{6}$ \\
\hline Carta Proemial & 4 & - & - & $\mathbf{4}$ \\
\hline Areúsa & 1 & 1 & - & $\mathbf{2}$ \\
\hline Tristán & 1 & - & - & $\mathbf{1}$ \\
\hline Sosia & 1 & - & - & $\mathbf{1}$ \\
\hline
\end{tabular}

$7 \quad$ Este rasgo ya se encuentra presente en La Celestina, especialmente en Melibea (al hablar de esposas infieles o de malos hijos) y en el planto final de Pleberio. En sus continuaciones también encontraremos presente esta característica, aunque (como veremos más adelante) es en La Tragedia de Lisandro y Roselia donde este recurso se emplea de una forma más extrema.

8 Se han omitido en estas gráficas todos aquellos personajes que no pronuncian ninguna cita erudita. Además, esta estadística se ha centrado exclusivamente en aquellas citas basadas en antropónimos o topónimos, excluyendo aquellos aforismos o comentarios en los que no se especificaba de forma explícita el autor de los mismos. 


\begin{tabular}{|c|c|c|c|c|}
\hline Traso el Cojo & 1 & - & - & $\mathbf{1}$ \\
\hline Barbanteso & 1 & - & - & $\mathbf{1}$ \\
\hline TOTAL & $\mathbf{8 3}$ & $\mathbf{4 2}$ & $\mathbf{2}$ & $\mathbf{1 2 7}$ \\
\hline
\end{tabular}

Tabla sobre las citas eruditas de La Tercera Celestina

\begin{tabular}{|c|c|c|c|c|}
\hline Personaje / Apartado & Antigüedad Clásica & Tradición Cristiana & $\begin{array}{c}\text { Edad Media y } \\
\text { Época Coetánea }\end{array}$ & TOTAL \\
\hline Poncia & 20 & 3 & 2 & $\mathbf{2 5}$ \\
\hline Penuncio & 13 & 2 & 5 & $\mathbf{2 0}$ \\
\hline Felides & 10 & 5 & - & $\mathbf{1 5}$ \\
\hline Sigeril & 9 & 3 & - & $\mathbf{1 3}$ \\
\hline Celestina & 4 & - & - & $\mathbf{4}$ \\
\hline Polandria & 3 & - & - & $\mathbf{3}$ \\
\hline Elicia & 1 & 1 & 1 & $\mathbf{2}$ \\
\hline Perucho & 1 & - & - & $\mathbf{2}$ \\
\hline Bravonel & 1 & - & - & $\mathbf{1}$ \\
\hline Calverino & 1 & - & - & $\mathbf{1}$ \\
\hline Canarín & 1 & - & - & $\mathbf{1}$ \\
\hline Rodancho & 1 & - & $\mathbf{9}$ & $\mathbf{8 8}$ \\
\hline TOTAL & $\mathbf{6 5}$ & $\mathbf{1 4}$ & & \\
\hline
\end{tabular}

Tabla sobre las citas eruditas de La Tragicomedia de Lisandro y Roselia

\begin{tabular}{|c|c|c|c|c|}
\hline Personaje / Apartado & Antigüedad Clásica & Tradición Cristiana & $\begin{array}{c}\text { Edad Media y } \\
\text { Época Coetánea }\end{array}$ & TOTAL \\
\hline Eubulo & 223 & 13 & 21 & $\mathbf{2 5 7}$ \\
\hline Elicia/Celestina & 73 & 10 & 1 & $\mathbf{8 4}$ \\
\hline Lisandro & 64 & 7 & - & $\mathbf{7 1}$ \\
\hline Prólogo & 57 & 3 & 1 & $\mathbf{6 1}$ \\
\hline Cartas finales & 51 & 10 & - & $\mathbf{6 1}$ \\
\hline Oligedes & 34 & 4 & 3 & $\mathbf{4 1}$ \\
\hline Casajes & 36 & - & - & $\mathbf{3 6}$ \\
\hline Brumandilón & 17 & 3 & 2 & $\mathbf{2 2}$ \\
\hline Escena letrados & - & 6 & 12 & $\mathbf{1 8}$ \\
\hline Roselia & 7 & - & - & 7 \\
\hline Drionea & 3 & - & - & $\mathbf{3}$ \\
\hline TOTAL & $\mathbf{5 6 5}$ & $\mathbf{5 6}$ & $\mathbf{4 0}$ & $\mathbf{6 6 1}$ \\
\hline
\end{tabular}

El análisis de esta tabla permite comprobar algunos datos interesantes: en primer lugar, si partimos de una edición conjunta de las obras (Segundas Celestinas, editada por Rosa Navarro Durán en Biblioteca Castro en 2016), y que por lo tanto siga criterios de publicación idénticos, podemos apreciar que, efectivamente, el abuso de la erudición en la obra de Muñón es mucho mayor, pues se multiplican por diez el número de citas 


\section{Luis García Valiente / IES Bonifacio Sotos de Casas Ibáñez Antonia Martínez Pérez / Universidad de Murcia}

pese a que es sensiblemente menos extensa que las composiciones de Silva y de Gómez: sale a una media de 3'17 citas por página frente a La Segunda Celestina, que promedia 0'36; y a La Tercera Celestina, que se quedaría en un irrisorio 0,26.

Y si tomáramos como referencia la única edición conjunta que existe de estas continuaciones junto a su obra modelo (editada por Manuel Criado de Val para Planeta, 1976) e incluyésemos en liza a La Tragicomedia de Calisto y Melibea de Fernando de Rojas $^{9}$, la obra de Silva obtendría un 0'37 de citas eruditas por página, la de Gómez de Toledo presentaría 0'26 y la composición de Muñón se dispararía hasta una media de 3'38 alusiones por página ${ }^{10}$. En cambio, la obra modelo contiene una media 0,65 por lo que es ligeramente más alta que La Segunda Celestina y La Tercera Celestina, pero se queda muy atrás respecto a las cifras presentadas por la Tragicomedia de Lisandro y Roselia. Somos conscientes de que este método puede parecer más acorde a un sistema científico que a uno literario, pero nos hemos decidido a incluirlo porque demuestra de una forma objetiva la diferencia de citas eruditas volcadas en las obras.

Como vemos, la inmensa mayoría de las citas están relacionadas con la Antigüedad Clásica, ya sea a través de sus sabios o de su mitología (un hecho en plena consonancia con el espíritu humanista del periodo renacentista). Concretamente suponen el 65\%, el $73 \%$ y el $85 \%$ de las citas eruditas de las obras de Silva, Gómez y Muñón, respectivamente.

Además, hay otras observaciones interesantes: como ya dijimos anteriormente, no resulta del todo verosímil que los criados de La Tragicomedia de Lisandro y Roselia sean tan doctos (un ejemplo de ello es Casajes, el escudero de Beliseno, quien intenta convencer a su señor con una larguísima lista de adulterios en personajes clásicos y mitológicos, comenzando por Filipo de Macedonia y acabando con Menelao). O siguiendo en esta línea, tampoco es verosímil que solamente el criado Eubulo ya realice el doble de citas eruditas que en toda La Segunda Celestina y La Tercera Celestina juntas. A este respecto, Menéndez Pelayo califica el monólogo final de Eubulo de "declamación contra el amor, atestada de lugares comunes y de una pedantería escolástica que supera a la de Pleberio, a la de Melibea y a todo lo creíble: apenas hay nombre de la antigüedad que no figure en aquella enumeración descabellada" (1943: 96). Además, otro momento en el que se abusa de los conocimientos del autor es en el episodio de los letrados, donde se dedica una escena entera a la exposición de una serie de argumentos sobre la validez o la invalidez de la palabra de matrimonio dada por el estudiante Sancias. A nuestro parecer -aunque es evidente que Muñón deseaba demostrar sus conocimientos sobre el tema-, este inciso rompe el devenir de la acción, es un paréntesis excesivo.

Sin embargo, y en descargo del autor de La Tragicomedia de Lisandro y Roselia, debemos señalar dos hechos: en primer lugar, si analizamos las referencias podemos comprobar que esas citas eruditas no se dan de forma homogénea a lo largo de toda la obra, sino que se amontonan exageradamente en determinados pasajes, por lo que

9 La obra de Rojas contiene un total de 166 de estas citas eruditas, sobresaliendo Melibea (35), Calisto (31) y Pleberio (22).

10 Las diferencias comparativas entre la edición de Planeta y Biblioteca Castro se deben, obviamente, a que ambas editoriales han seguido distintos criterios tipográficos, aunque resulta significativo que las diferencias hayan resultado mínimas. 
se acentúa la sensación de hartazgo. En segundo lugar, debemos destacar que -al igual que sostiene Lida de Malkiel- el alarde de la cultura adquirida era una práctica habitual en la época; a este respecto Pérez Priego destaca:

El Renacimiento [...] no logrará todavía despegarse de los hábitos escolares y del gusto enciclopédico. [...] no deja de rendir culto a las recopilaciones sistemáticas y exhaustivas de los dichos, sentencias, hazañas, prodigios, pensamientos y lugares comunes del pensamiento grecolatino. Ese culto en buena medida viene introducido desde los libri minores que se estudiaban en la escuela, lo que termina contagiando a muchas obras de la época de un inmoderado abuso de citas y de erudición (2011: 202).

Es decir, estamos ante algo normal para el momento ${ }^{11}$. En la misma línea, Rosa Navarro Durán incide en que los discursos moralizantes cargados de pesada erudición tienen su explicación en que "no era fácil para un humanista dejar de mostrar el saber acumulado en los estudios $\mathrm{y}$, por otra parte, hacerlo era rasgo preceptivo del género celestinesco" (Muñón 2009: 22). Pero aun con toda esa erudición, Menéndez Pelayo acaba calificándola de "joya literaria" y destaca su "sabrosa lectura", pues a juicio del estudioso cántabro, es "la mejor hablada de todas las Celestinas después de la primera, de cuyo aliento general carece, pero a la cual supera en elegancia y atildamiento de dicción, como nacida en un periodo más clásico de la prosa castellana" (1943: 90). Sin embargo, y a pesar de que sea algo común en la época, llama poderosamente la atención que haya tal disparidad de criterios en cuanto al alarde de erudición, cuando las tres continuaciones se publican en un margen de apenas ocho años (1534, 1536 y 1542), lo que inequívocamente nos conduce a diferencias estilísticas entre los diferentes autores.

Ajena a toda esta erudición está La Tercera Celestina. Como hemos podido comprobar, es la obra que menos referencias eruditas recoge, y también es la única que no introduce ninguna en el prólogo. Pero a diferencia de Silva, donde estas estaban repartidas de forma homogénea, aquí la mayoría se amontonan en el primer tercio de la composición, especialmente durante la discusión misógina entre Poncia y el hortelano Penuncio -es más: este pasaje representa el $48^{\prime} 86 \%$ de las citas eruditas de toda la obra de Gómez de Toledo-; mientras que, a excepción de una alusión a Platón que se realiza en la última página, no se encuentra ni una sola cita en los dos últimos tercios de la obra. Pero, ¿por qué se produciría este cambio estilístico de forma tan abrupta? Quizá el autor usó para la elaboración de los primeros auctos uno de esos cuadernillos de apuntes que comentábamos anteriormente y después ya no pudo disponer de él, o simplemente creyó que lo más conveniente para la correcta transmisión de la trama sería un estilo distinto.

No obstante, también llama la atención el hecho de que sean criados como Poncia, Sigeril y Penuncio quienes encabecen la lista de citas frente a los jóvenes señores o frente a Celestina, la reina de la palabra. Por lo que, al igual que ocurría en la obra de Muñón, no

11 Un ejemplo de ello lo proporciona Eugenio Asensio, quien refiriéndose a la Comedia Eufrosina afirma que "cualquier tema pescado por los cabellos, la audacia, la tardanza, la avaricia, la fortuna, sirve al autor para volcar sus cuadernillos de apuntes y soltar un rosario de nombres y una retahíla de máximas" (Vasconcellos 1951). 


\section{Luis García Valiente / IES Bonifacio Sotos de Casas Ibáñez Antonia Martínez Pérez / Universidad de Murcia}

resulta del todo verosímil que un hortelano sea capaz de emitir todas esas enumeraciones de personajes históricos y mitológicos, o que el criado Sigeril sepa que "Marco Tulio escrivió «De amicicia»" (Gómez de Toledo 1973: 103). Y a pesar de ello, el único pasaje donde realmente se hace ostentación erudita es el ya mencionado de Poncia y Penuncio, pero al ser dialogado ese retoricismo resulta más llevadero, pues las retahílas de datos son más cortas que, por ejemplo, los largos sermones de Eubulo en La Tragicomedia de Lisandro y Roselia.

Sin embargo, Menéndez Pelayo calificó la obra de Gómez de Toledo como "la más rara de esta serie de libros, aunque a esta rareza se reduce todo su mérito" (1943: 80-81); y la definió como "tedio" e "insípida rapsodia" (1943: 90), llegando incluso a declarar un juicio durísimo: "la tabla de los cincuenta actos en que se divide, con la cual podría excusarse la lectura, enteramente inútil, de tan necia y soporífera composición" (1943: 81-82). Además, el sabio santanderino prosigue: "la fábula es insulsa y deslavazada, el estilo confuso, incorrecto y a veces bárbaro" (1943: 83). Pero, ¿por qué motivos ataca tanto su estilo y lo califica de "confuso"? La respuesta es muy sencilla: el abuso de las figuras de repetición (derivatio y poliptoton ${ }^{12}$ ) que provocan que los discursos de los personajes se traben continuamente; y esto es fácilmente comprobable, por ejemplo, en que La Tercera Celestina tiene un ritmo más lento que La Segunda Celestina pese a que Silva desarrolla decenas de historias amorosas a la vez, ya que son estas figuras quienes lo ralentizan reiteradamente ${ }^{13}$.

No obstante, Criado de Val cree que el de esta obra es un caso extremo de mala fortuna literaria derivada de la crítica "dura e injusta" de Menéndez Pelayo, pues "habrá muy pocas obras de nuestra literatura del siglo XVI que se le puedan comparar en cuanto se refiere al ambiente, al lenguaje o al detalle descriptivo ${ }^{14}$, , convirtiéndola en un antecedente de nuestro costumbrismo. Y así es, pues son dignas de mención las descripciones que el paje Corniel hace de los trajes y atavíos preparados para la boda de Felides; las minuciosas referencias a una boda de aquella época (con todos sus convencionalismos, peticiones y cortejos previos) y las actuaciones de la justicia frente a brujas y alcahuetas.

Por último, querríamos resaltar que pese a que Gaspar Gómez no introduce largos sermones eruditos, sí incluye grandes discursos de carga moralizante y reprobadora, como por ejemplo los que realizan los vecinos tras la muerte de Areúsa (y que parece un resumen moral de los atropellos de Celestina (Gómez de Toledo 1973: 333) o ante

12 La derivatio es una figura literaria de repetición que consiste en el uso de palabras que pertenecen a la misma familia léxica, y que por tanto, comparten el mismo lexema; mientras que el poliptoton es una figura cuya alteración gramatical se fundamenta en morfemas flexivos, frente al anterior tipo, de carácter derivativo (Azaustre; Casas 1997: 100-102). Los ejemplos son continuos: "¡Oh dolor terrible para doler!; ¿con qué recebimiento seré recebido?; no tienes mucha razón en tus razones...".

13 Ya nos podemos hacer una idea de lo que será el resto de la obra cuando solamente en el Prólogo dedicado a Feliciano de Silva -menos de dos páginas- encontramos estos recursos en dieciocho ocasiones. Además, estas figuras no son patrimonio exclusivo de un único personaje, sino que no hay ninguno que no las use, y en multitud de ocasiones. Posiblemente la admiración que Gómez siente hacia Silva le haya hecho tomar este recurso que se encuentra en el primer parlamento que realiza Felides en La Segunda Celestina. Sin embargo, debemos tener en cuenta que Silva prácticamente solo la usa aquí, empleándolo únicamente con este personaje y con la finalidad de parodiarlo; mientras que en Gaspar Gómez hay una abuso generalizado que da como resultado un lenguaje antinatural que supera cualquier pretensión retórica, pues traba y ralentiza continuamente la viveza de los parlamentos. Es como si este autor no hubiera comprendido la sutileza paródica de Silva, o por el contrario, pretendiese llevarla hasta el extremo. Por ello consideramos que el abuso de estas figuras rompe en exceso la verosimilitud expresiva en La Tercera Celestina.

14 (Rojas; Silva; Gómez de Toledo; Muñón 1976: XLVIII). 
el cadáver de la vieja alcahueta (Gómez de Toledo 1973: 379-380), y que tiene como receptores al mundo y a Fortuna, recordando los plantos que realizan Pleberio o Eubulo para cerrar otras obras del ciclo celestinesco. Pero sin lugar a dudas, es muy destacable el personaje de Dárdano (hermano de Paltrana), pues da la impresión de que, al igual que Eubulo supone una especie de alter ego de Sancho de Muñón, este encarna el de Gómez de Toledo: su primera aparición es cuando sale de escuchar misa y hace alusión dos veces más a la importancia de esta actividad, se muestra educado en todo momento (se insiste mucho en que pide permiso para entrar en casa de su hermana y de su amigo Felides, pese a que ellos rechazan tanta formalidad), realiza numerosos razonamientos sobre los más diversos temas, el matrimonio, los consejos, el saber escuchar, etc.), y en definitiva, como decimos, se nos presenta como hermano de Paltrana y amigo de Felides. Es decir, encarna el nexo de unión entre la pareja de enamorados y el exterior (algo equiparable a la propia figura de Gómez de Toledo), y, gracias a su intervención, se conciertan finalmente los casamientos (recordemos que por esos instantes Celestina desaparece momentáneamente de la trama debido a que es encorozada y emplumada en la plaza), de igual modo que gracias a Gómez de Toledo se producen las bodas que no llegaron a concluirse con Silva.

Por lo tanto, nos encontramos con tres obras que siguen unas mismas huellas genéricas, pero en las que el estilo de cada uno de los autores (y la finalidad que perseguían) ha sido determinante. Pese a que la ornamentación erudita era una constante estilística durante el Renacimiento, Silva y Gómez las emplearon en dosis adecuadas que no entorpecieran el mensaje que intentaban transmitir, mientras que Muñón (que vuelve fielmente al modelo de Rojas para advertirnos ${ }^{15}$ ) trata de conseguir que "la dificultosa y amarga doctrina de la verdad y la virtud" que se alcance sea más llevadera "junto con el dulzor de la fábula" (Muñón 2009: 89), haciendo buenas las palabras de Rosa Navarro Durán: "Si para el fin didáctico y moralizante de la obra, las espinas son la fábula, y las rosas, la moralización, para el lector de hoy es justo lo contrario" (Muñón 2009: 60). Diferentes formas de comprender el legado de todo un género y que lo enriquecen con sus diferentes enfoques.

\section{BIBLIOGRAFÍA}

AZAUSTRE, Antonio; CASAS, Juan (1997): Manual de retórica española. Madrid: Ariel. BARANDA LETURIO, Consolación; VIAN HERRERO, Ana (2007): "El nacimiento crítico del «género» celestinesco: historia y perspectivas", Raquel Gutiérrez y Borja Rodríguez (coord.), Orígenes de la novela. Estudios. Servicio de publicaciones de la Universidad de Cantabria. $<$ http://www.cervantesvirtual. com/nd/ark:/59851/bmc54348>

GALLARDO, Bartolomé José (1863-89): Ensayo de una biblioteca española de libros raros y curiosos. III. Madrid: Rivadeneyra.

GÓMEZ DE TOLEDO, Gaspar (1973): Tercera parte de la tragicomedia de Celestina, ed. Mac Eugene Barrick. Filadelfia: University of Pennsylvania Press.

15 El autor afirma que compuso "este libro lleno de avisos y buenas enseñanzas de virtud sacadas de muchos autores santos y profanos, con celo de utilidad pública" y que aunque se relaten unos vicios no es la intención del autor alabarlos, sino que lo hace porque la verdad, envuelta en una fábula, ayuda a entender esa verdad. 
HEUGAS, Pierre (1973): «La Célestine» et sa descendance directe. Burdeos: Institut d'études ibériques et ibéro-americaines de l'université.

JAUSS, Hans-Robert (1987): "El lector como instancia de una nueva Historia de la Literatura", José Antonio Mayoral (comp.), Estética de la Recepción. Madrid: Arco/Libros.

LIDA DE MALKIEL, María Rosa (1962): La originalidad artística de «La Celestina». Buenos Aires: Eudeba.

LÓPEZ IZQUIERDO, Marta (2008): "Personaje y lengua en «La Celestina»: nuevas perspectivas de estudio", Celestinesca. 32: 165-189. < https://www.academia. edu/8619168/2008 Personaje y lengua en La Celestina nuevas perspectivas de estudio Celestinesca 322008 p. 165 189>

MENÉNDEZ PELAYO, Marcelino (1943): Orígenes de la novela. IV. Santander: Aldus-CSIC.

MUÑóN, Sancho de (2009): Tragicomedia de Lisandro y Roselia, ed. Rosa Navarro Durán. Madrid: Cátedra.

PÉREZ PRIEGO, Miguel Ángel (2011): La edición de textos. Madrid: Síntesis.

ROJAS, Fernando de (1994): La Celestina, ed. Dorothy S. Severin. Madrid: Cátedra.

ROJAS, Fernando de; SILVA, Feliciano de; GÓMEZ DE TOLEDO, Gaspar; MUÑÓN, Sancho de (1976): Las Celestinas, ed. Manuel Criado de Val. Barcelona: Planeta. SILVA, Feliciano de (1988): Segunda Celestina, ed. Consolación Baranda. Madrid: Cátedra. SILVA, Feliciano de; GÓMEZ DE TOLEDO, Gaspar; MUÑÓN, Sancho de (2016): Segundas Celestinas, ed. Rosa Navarro Durán. Madrid: Biblioteca Castro.

VASCONCELLOS, Jorge Ferreira de (1951): Comedia Eufrosina, ed. Eugenio Asensio. Madrid: CSIC.

\section{PERFIL ACADADÉMICO Y PERSONAL}

Luis García Valiente es licenciado en Filología Hispánica por la Universitat de València y posee un Máster en Formación e Investigación Literaria y Teatral en el Contexto Europeo en la especialidad de Metodologías, Teorías y Técnicas de Investigación en la Literatura Española e Hispanoamericana por la UNED. Actualmente es estudiante de Doctorado por la Universidad de Murcia y profesor de Educación Secundaria de Lengua Castellana y Literatura en Casas Ibáñez (Albacete).

Antonia Martínez Pérez es Catedrática de Filología románica, adscrita al Departamento de Filología Francesa, Románica, Italiana y Árabe de la Universidad de Murcia. Sus líneas de investigación giran en torno a la literatura medieval, sobre la que ha publicado varios libros, entre otros, La transformación de la Lírica Francesa Medieval. Poesía de inspiración urbana en su contexto románico (S.XIII), Universidad de Granada, 2013; así como traducciones de textos literarios medievales, el último sobre los Versos de la Muerte. Robert le Clerc d'Arras y Adam de la Halle, Disbalelia, 2016.

Fecha de recepción: 13/05/2019

Fecha de aceptación: 26/06/2019 